\title{
Perspectives on Salutogenesis of Scholars Writing in Portuguese
}

\author{
Luis Saboga-Nunes
}

\section{Introduction}

In 1994, Aaron Antonovsky made a trip to Lisbon, where he was the special guest at the post-graduation series of conferences held at the Lisbon Faculty of Medicine. During this conference, professional translators were not always able to maintain a steady discourse since they lacked the vocabulary to translate his concepts. Several translator silences left Antonovsky's words unaccounted for; many in the audience could not follow him in English. Words and terms like salutogenesis, sense of coherence, comprehensibility, manageability, meaningfulness, and generalized resistance resources, were left untranslated, giving each participant the freedom to find the best words to link those concepts together into the framework of the new paradigm (Antonovsky, 1985). Following the conference in a private meeting with the present author, Antonovsky took time to review his ideas and clarify several questions about the relevance of the salutogenic perspective in different social contexts.

After returning to Israel, Antonovsky honored my request, and sent all of his salutogenesis newsletters to Lisbon, among other relevant materials. Following this first exchange and to get more deeply into the salutogenic paradigm, I sent a letter to Antonovsky with new queries. A short reply from his secretary informed me that Professor Antonovsky had passed away. Only a few weeks after the Lisbon conference, he had succumbed to a myeloid leukemia.

L. Saboga-Nunes $(\bowtie)$

Public Health Research Center, Department of Health Strategies and Health Promotion, National School of Public Health, Universidade NOVA de Lisboa, Lisbon, Portugal

e-mail: saboga@hotmail.com
The process of introducing Antonovsky's insights in Portugal suffered some suspicion and opposition. My proposal to expand salutogenesis research into the Portuguese context was not readily accepted at first by the Board of the Scientific Council of one of the major faculties in the field of health sciences. It was only after the persistent intervention of Professor Sampaio de Faria, who had been at the World Health Organization's Copenhagen headquarters, that barriers were surmounted. The first major piece of Portuguese research took place between 1997 and 1999, with the validation in Portuguese of the Orientation to Life Questionnaire (Saboga-Nunes, 1999). From there, several theses, articles, programs, conferences, research grants proposals, and even top level governmental programs recognized the relevance of the salutogenic paradigm. Today several training programs at the National School of Public Health in Lisbon carry the salutogenic blueprint, and throughout the country, several faculties in the health sciences include salutogenesis in their curricula. This has also been the case in other Portuguese-speaking countries, like Brazil. Today, instead of being met with suspicion, salutogenesis is recognized as a legitimate research and intervention paradigm in Portuguese-speaking countries.

\section{Antonovsky's Legacy Travels to the Web and Salutogenesis Goes Virtual}

Antonovsky's sudden departure led to a void. This is the context that launched the first internet website on salutogenesis. The goal was to make his ten salutogenesis newsletters accessible in electronic format to all researchers, along with the first database on salutogenesis (Karraker \& Grochowski, 2001). Special permission from Professor Antonovsky's wife, Helena, with whom I continued to correspond and request and receive materials, helped to establish the pool of resources for the new website. Three years after Antonovsky's visit to Lisbon, the first website 
dedicated to the sense of coherence (http://www.angelfire. com/ok/soc) was activated from Lisbon. Following the increasing number of site accesses and information processing demands, a new design and internet protocol was established at http://www.salutogenesis.net in the beginning of 2002, providing a more efficient web tool to empower researchers working with the salutogenic paradigm. This helped to disseminate salutogenesis research progress not only in Portuguese, but in five other major languages as well.

\section{Salutogenesis Research in Portuguese}

Translation of the 13-item Orientation to Life Questionnaire (OLQ) (short version) to Portuguese was done in 1994 (Geada, 1994). Full translation and subsequent validation of the 29-item OLQ (Questionário Orientação para Viver (QOV) was undertaken in 1999 (Saboga-Nunes, 1999). Portuguese research on OLQ measurement (psychometric properties, reliability, validation, and factorial analysis) helped to establish its cultural relevance, with contributions from both quantitative and qualitative methodologies. It linked the sense of coherence with stress management and mental health. Antonovsky's proposal is that a personal disposition, that he called the sense of coherence, can best predict stress outcomes. Also, the relationship between the sense of coherence and physical and mental health was observed in the Portuguese social context. This research generated new evidence to inform the development of intervention to strengthen the capacity of people to cope, in a healthy manner, with stress resulting from traumatic and psychosocial factors, as well as with endemic stress.

The Portuguese research also highlighted the relevancy of the generalized resistance resources concept and illuminated their importance for individuals' capacity to cope with stress. In the continuum functional/dysfunctional, a person with a high sense of coherence manages and functions better. A low sense of coherence is related with poor health management. This construct, taken as an independent variable and not as an instrument to evaluate health, is fundamentally composed of social factors. It is definitively an instrument of analysis that allows us to see health as something more global (WHO's definition of health). These conclusions, in the Portuguese context, are anchored in the results of the study that involved a sample of 643 persons asked to fill in a questionnaire to provide examples of stressful situations, and report what specific behaviors were activated in these situations (SabogaNunes, 1999). This sample gathered together information from different parts of Portugal and included mainly people who were not declared sick and were living their lives on an everyday regular basis. A variety of measures were obtained including anxiety, locus of control, coping efficiency, social networking, social support, personal disposition, health-related lifestyle behaviors, and outcomes including health and satisfaction. Age as well as social, educational and economic strata, gender, and a number of life stress situations mentioned by each individual were considered as confounding elements. The results support Antonovsky's (1987) suggestion in the Portuguese context, that the sense of coherence is relevant in managing stressful events and helping people remain both physically and psychologically healthy. Further, this study suggests that people from Portugal can also develop similar levels of the sense of coherence as in other cultures. Finally, it established the psychometric properties of the Portuguese version of the QOV. It was predicted that the QOV would demonstrate reliability, satisfactory internal consistency, and test-retest reliability. On the validity level it focused on content, face, and consensual, before considering convergent and discriminant validity with the multi-method multi-trait method, known groups validity and criterion validity. Exploratory factor analytic procedures to examine the factor structure of the QOV were undertaken (SabogaNunes, 1999). Results indicated satisfactory internal reliability as demonstrated by a high Cronbach's alpha coefficient (between 0.83 and 0.90), in line with the range of results found with the English version sense of coherence (Cronbach's Alpha 0.84-0.93) (OLQ). The negative correlation between the QOV, perception of stress and anxiety suggest the external validity of the scale. Test-retest reliability analysis provided high correlations $(r=0.88)$ between groups. Discriminant validity suggests that the QOV is correlated with social network, and with locus of control. Principal components analysis produced a solution with eight factors, which were further reduced to only one factor, suggesting that the QOV is a unidimensional instrument.

Convergent validity was examined; locus of control was related to the QOV $(r=0.36)$ at a magnitude similar to the OLQ $(r=0.39)$, and self-perceived health was correlated with the QOV $(r=0.31)$. Discriminatory validity was explored with anxiety, with which the QOV was correlated at a similar magnitude $(r=0.27)$ as was the OLQ $(r=-0.21)$. In addition, the QOV was negatively correlated with isolation $(r=-0.45)$ and stress $(r=-0.23)$, as expected based on OLQ in English (Saboga-Nunes, 1999).

Antonovsky proposed that the sense of coherence is stabilized in adulthood. In a test of this assumption with the QOV, a test-retest of the scale showed stability between 
Fig. 46.1 Mapping the words to find the core etymology of the sense of coherence concept in Portuguese (sentido de coerência, senso de coerência and sentido interno de coerência). Source: Open Access Portuguese Institutional Repositories, RCAAP, 2015

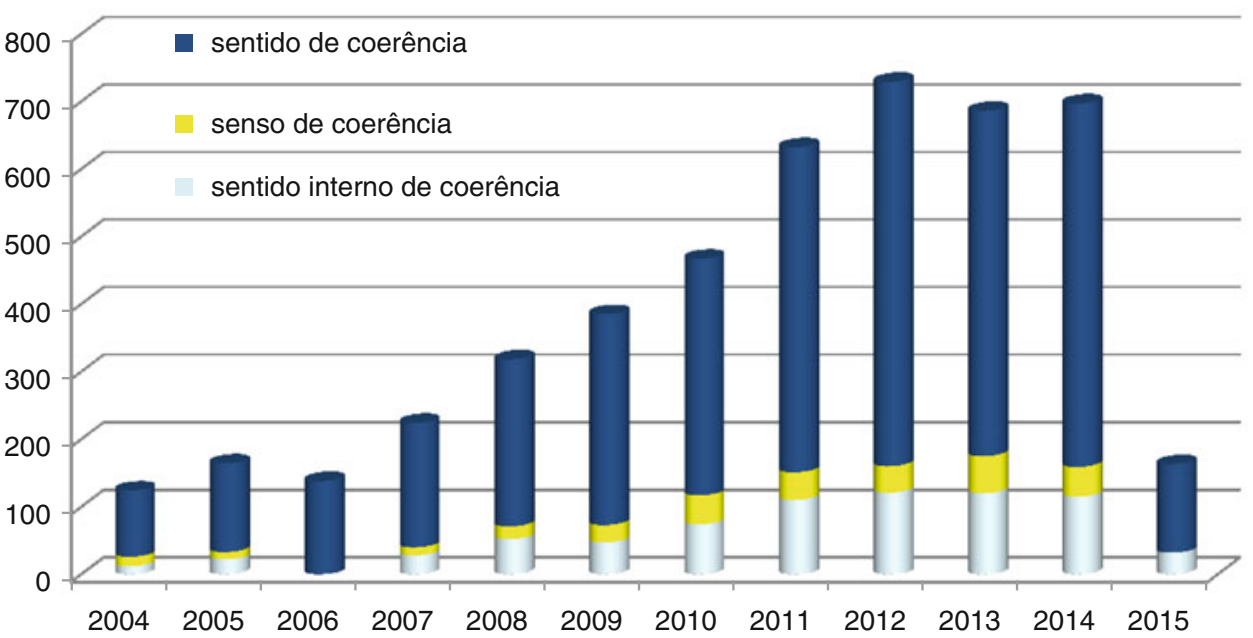

time one and time two $(r=0.88)$ in the Portuguese validation research study (Saboga-Nunes, 1999). As this result started to be disseminated with the help of the website, several other researchers engaged the salutogenesis approach in Portugal and in Brazil.

\section{Translation Challenges}

Geada (1994) translated the sense of coherence into sentido interno de coerência, without any validation process (Saboga-Nunes, 1998). Later on, after a process of back translation and focus group discussions, the word interno was dropped since it was considered redundant. Thus, sentido de coerência was proposed as the culturally validated and adapted concept for the sense of coherence (Saboga-Nunes, 1999).

There are 838 occurrences of "sentido interno de coerência" in the literature between 2004 and 2015. Nevertheless, the main stream of usage is "sentido de coerência", with 4148 occurrences in Portuguese reference lists between 2012 and 2014. Through the years, Portuguese researchers have been dedicating more and more interest to the construct (numbers of citations are in the parentheses): 2014 (538), 2013 (511), 2012 (569), 2011 (481), 2010 (350), 2009 (312), 2008 (247), 2007 (184), 2006 (138), 2005 (131). By publication type, these occurrences are distributed as follows: master theses (1991), articles (1005), conference presentations (326), other (86), doctoral dissertations (316), part of book or chapter of book (136), bachelor's theses (87), books (66), reports (75), research paper (30) (Open Access Portuguese Institutional Repositories, RCAAP, 2015).

A shift from this main stream usage (that is the translation of the sense of coherence by sentido de coerencia) occurred with a translation to Portuguese (in a Spanish journal) of proceedings from Bengt Lindström's conference on resiliency in 2001 (Lindstrom, 2001). The translator could not find the right word in Portuguese for the sense of coherence concept, and did a transliteration by using the Spanish word "senso" for sense, transliterating sense of coherence into senso de coerência. From this, a tradition started, mainly in the Brazilian literature. In 2007, the Brazilian nurse Dantas, aiming at validating the sense of coherence scale in Portuguese, referred to the sense of coherence not as sentido de coerência but as senso de coerência (Dantas, 2007). A summary of usage of the various translations is given in Fig. 46.1 .

In Portuguese, salutogénese (salutogenesis) is used very rarely compared to use of the various translations of the sense of coherence; just 19 occurrences have been found: master's theses (7) doctoral theses (5) other (3) article (3) book (1) (Open Access Portuguese institutional repositories, RCAAP, 2015).

\section{Salutogenesis Research in Portuguese}

\section{Salutogenesis and Brucellosis}

Brucellosis (an infectious disease caused by the Brucella bacteria that can spread from animals to humans) is a serious public health issue. Dealing with it can be a challenge because of the environmental and contextual factors that influence its recurrence. Brito (2004) used the salutogenesis approach to build an intervention to tackle brucellosis incidence. A community intervention was proposed to decrease Brucellosis incidence in Serra da Estrela (Portugal), where it is about 50 times higher than in the country as a whole. Brito (2004) proposed an education model inspired by the salutogenic perspective and consciousness-raising (Freire's model). She found it effective in modifying breeders' 
knowledge, beliefs, and attitudes regarding brucellosis control. A community-based intervention launched during 2004-2005 was intended to educate 27 groups of breeders plus their relatives and neighbors (Brito 2004). With a culturally designed course to prevent brucellosis, the sense of coherence showed a significant impact on the process of increasing knowledge/consciousness about brucellosis and modifications of attitude through the National Plan of Brucellosis Eradication.

\section{Smoking Cessation}

In Portugal the prevalence of smokers over 15 years of age is $25 \%$ (Eurobarometer 429, 2015). While the strategy of helping people to quit smoking has been emphasized at National Health Service (NHS) level, the uptake of cessation assistance has exceeded the capacity of the service (Ferreira, 2008). This induced the search for new theoretical and practical venues to offer alternative options to people willing to stop smoking. Traditionally the pathogenic paradigm emphasizes a person-to-person approach, based on the "magic bullets" of medications (that are very expensive and unaffordable to many smokers). Alternatively, in order to test salutogenesis as a framework to address the problem of how to support intentions to make behavioral changes (IBC) and behavior changes (BC)—smoking cessation-a web-based intervention was set up in 2007 (Saboga-Nunes, 2012).

The theoretical framework of the sense of coherence was used to build this Web-Assisted Tobacco Intervention Probe (WATIP) at www.parar.net. A group of 3150 tobacco users answered initial eligibility questions. In the end, 1463 met all eligibility requirements, completed intake, decided on a day to quit smoking (Dday) and declared IBC, while a second group of 650 did not decide on a Dday. With two quit attempts made before joining the platform, most of the participants had experienced past failures while wanting to stop. These participants followed an intervention that was built specifically to reinforce their sense of coherence.

There were differences between groups in IBC reflecting the high and low levels of the sense of coherence score $(\mathrm{OR}=1.43, p=0.006)$; those who considered setting a Dday had higher levels of the sense of coherence. BC and the usability of the platform were explored a year after IBC was declared. In this study, the sense of coherence was associated with the decision to set a day to quit smoking and with smoking cessation (Saboga-Nunes, 2012). The website at (www.parar.net) is a healthy lifestyle intervention, structured according to the salutogenic paradigm to help people to move to a life without tobacco. More than 15,000 people have used information at this website to date.

\section{Salutogenesis and Families of People with Psychotic Disorders}

Pereira (2010) investigated salutogenesis in a cohort study of families of patients with psychosis in the Lisbon area. His aim was to analyze the importance of caregivers' sense of coherence as a protective factor for psychological distress, using data from the Families of Psychotic Patients (FAPS) Project. FAPS is a prospective study of a convenience sample of 108 primary caregivers to patients with ICD-10 schizophrenia, schizo-affective or delusional disorders, in community mental health services. Comprehensive caregivers' assessments included the Involvement Evaluation Questionnaire-IEQ, General Health QuestionnaireGHQ12, and the Orientation to Life Questionnaire (sense of coherence). Patients are given the BPRS (symptoms) and WHO-DAS II (disability). There were significant correlations between the sense of coherence and GHQ and IEQ (Gonçalves \& Saboga-Nunes, 2008). Stress-appraisalcoping paradigms have been prevalent in caregiving research, but their usefulness must not preclude testing salutogenic approaches (Antonovsky, 1979), as is the case in positively focused family interventions (Gonçalves, 2010).

Marques and Gonçalves (2014) also studied couples and families of people with psychotic disorders, using a qualitative research approach (combining in-depth individual and joint interviews), triangulated with the measures of the Portuguese version of the Orientation to Life Questionnairesense of coherence scale (Antonovsky, 1987; Saboga-Nunes, 1999) and the Quality of Carer-Patient RelationshipsQCPR. Results highlighted that diagnosis played an important role on the sense of coherence's comprehensibility component (life makes sense). Good pre-caregiving and current relationship were associated with carers' ability to cope, namely sense of coherence's manageability (problems will be bearable) and meaningfulness (life is viewed as a challenge). Her findings suggested that an understanding of QR and the sense of coherence prior to diagnosis may encourage positive patterns of care, foster successful adaptation to changing needs, and support in-home arrangements as long as possible (Marques \& Gonçalves, 2014).

\section{Salutogenesis and Maternal-Fetal Attachment}

Maternal-fetal attachment (MFA) is not yet a totally understood and well-operationalized concept. Nevertheless, it is well-established that MFA is a key determinant in health promotion to reduce risk factors or their impact on mother and child, and strengthen protective factors to increase resilience. MFA is also correlated with health practices during pregnancy that influence pregnancy and baby outcomes. 
Fig. 46.2 Links between the European Health Literacy framework (HLS-EU) and the Sense of Coherence model (respectively for the dimensions of comprehensibility (understanding \& knowledge), manageability (appraisal and competence), and meaningfulness (application and motivation)

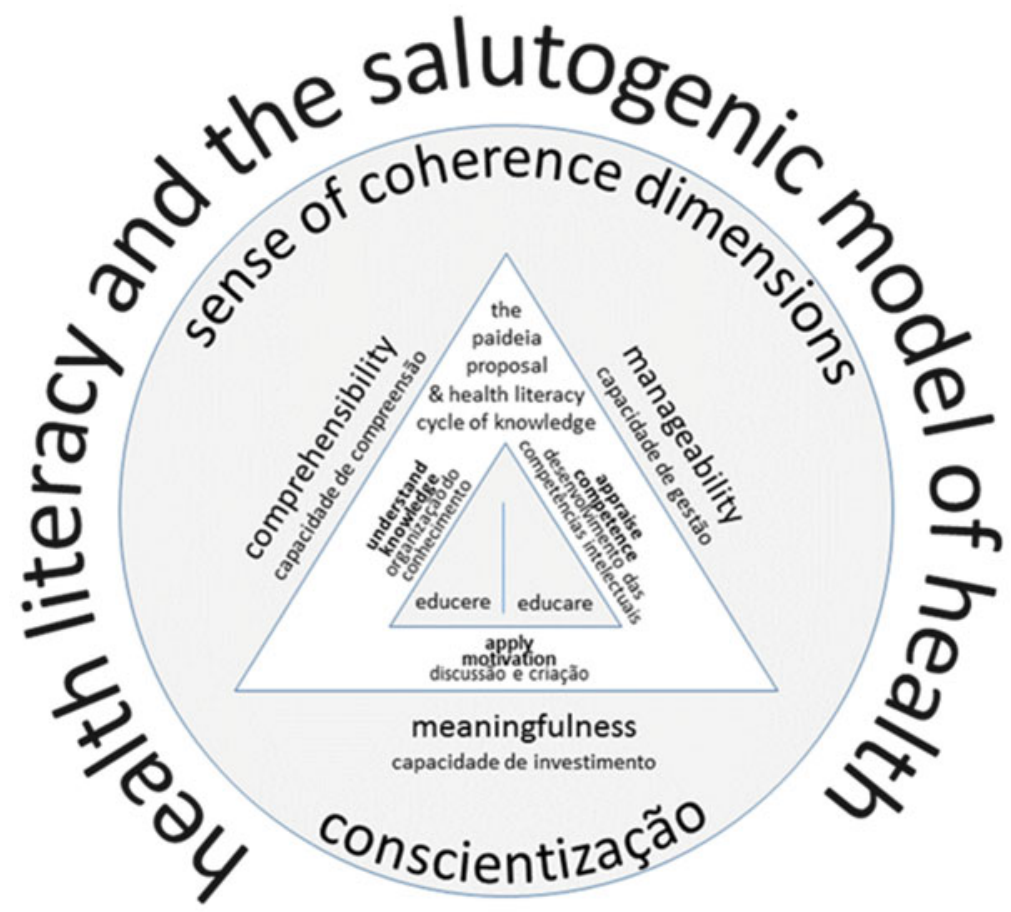

MFA seems a relevant concept for the future mother-baby interaction, but more studies are needed to clarify the concept and its operationalization. In research by Correia (2014), 92 pregnant women were recruited from the Maternal Health Consultation in Primary Health Care at Amadora, Portugal, who participated in these (among other) assessments at 12 and 20 weeks of pregnancy and 6 months after giving birth: sociodemographic data, the Edinburgh post-natal Depression Scale (EDPS), the General Health Questionnaire (GHQ), and the Sense of Coherence questionnaire. The association between psychosocial risk factors and MFA was mediated by depression and the sense of coherence, having a clear and opposite relevance to MFA. Pregnancy can be considered as a maturational process and an opportunity to change, where adaptation processes occur, buffering risk, decreasing depression, and increasing sense of coherence (Correia, 2014).

\section{Salutogenesis and Health Literacy: Moving Up in the Ladder of Health Promotion}

Although there are different approaches to discuss health literacy today, one of the latest that was developed-the European Health Literacy framework (HLS-EU) - connects closely to the sense of coherence (Fig. 46.2) (Saboga-Nunes et al., 2014).

Educators and the education settings can play a major role in promoting health literacy as a direct outcome (SabogaNunes et al., 2014). They also can contribute to build a strong sense of coherence in their students. In the CrAdLiSa project in Portugal, adolescents' health literacy and sense of coherence assessments were done with the Portuguesevalidated version of the European Health Literacy Survey, (Saboga-Nunes \& Sorensen, 2013), and the OLQ. A sample of 832 students participated in the CrAdLiSa project (Cavalheiro \& Saboga-Nunes, 2014). Reliability analysis of HLS-EU-PT dimensions show an internal consistency (Cronbach's alpha coefficient) of 0.946 (healthcare dimension), 0.947 (disease prevention dimension), and 0.958 (health promotion dimension), while the global instrument presents a value of 0.98 . The prevalence of inadequate health literacy was $4.2 \%$ and the prevalence of problematic health literacy was $25.6 \%$. The OLQ was internally consistent (Cronbach's alpha coefficient of 0.87 . There was a positive association between health literacy and the sense of coherence ( $r=0.49$ ), as depicted in Fig. 46.3.

Investigating further on the relationship between health literacy and the sense of coherence, results show that from Type 1 to Type 8 of participants' sense of coherence, there was a consistent increase in the level of health literacy (Fig. 46.4).

\section{Conclusion}

Since 1994, when Antonovsky visited Portugal, research on the salutogenesis paradigm has developed in different perspectives. The first stage of this development focused on struggling with the new concepts, their translation, and meaning in a different cultural setting than that of 
Fig. 46.3 Relation between health literacy (HLS-EU-PT) and the sense of coherence $(r=0.4872, p=0.001)$. Source: CrAdLiSa project, 2014

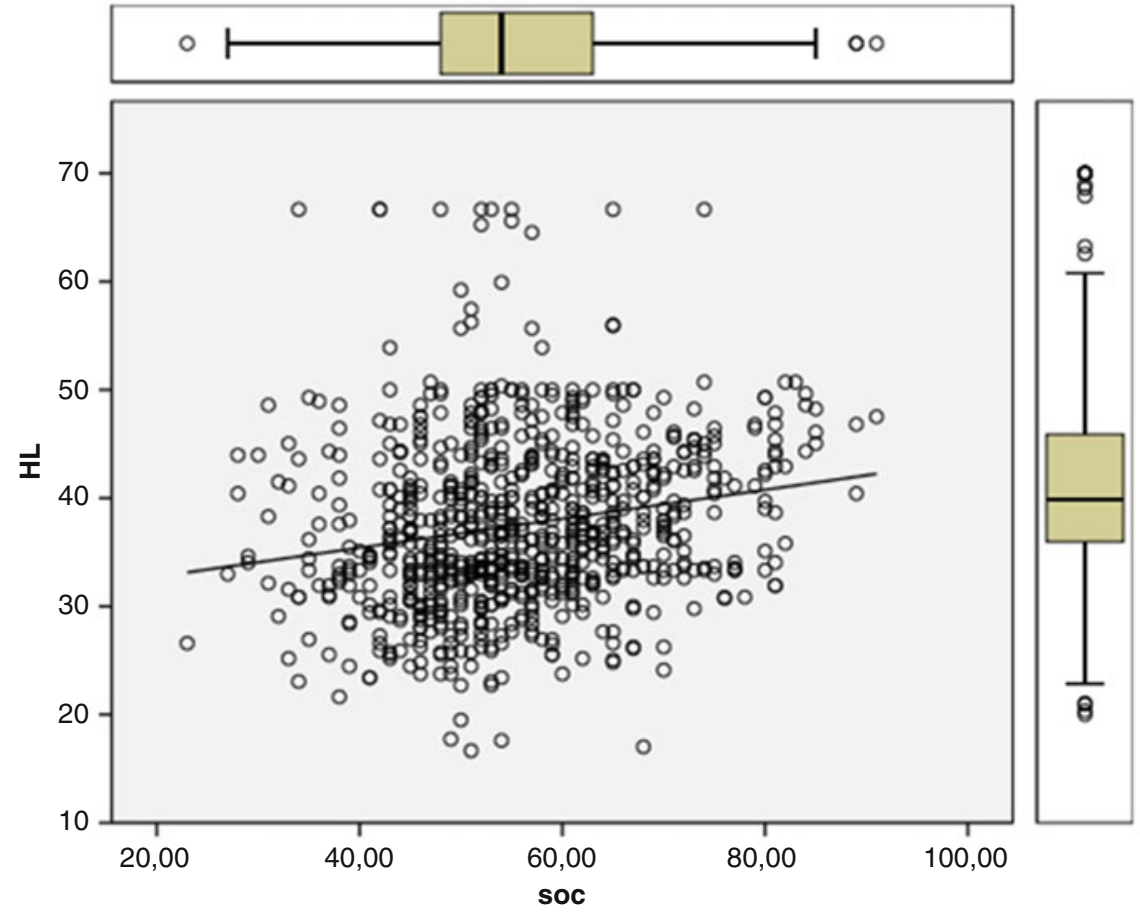

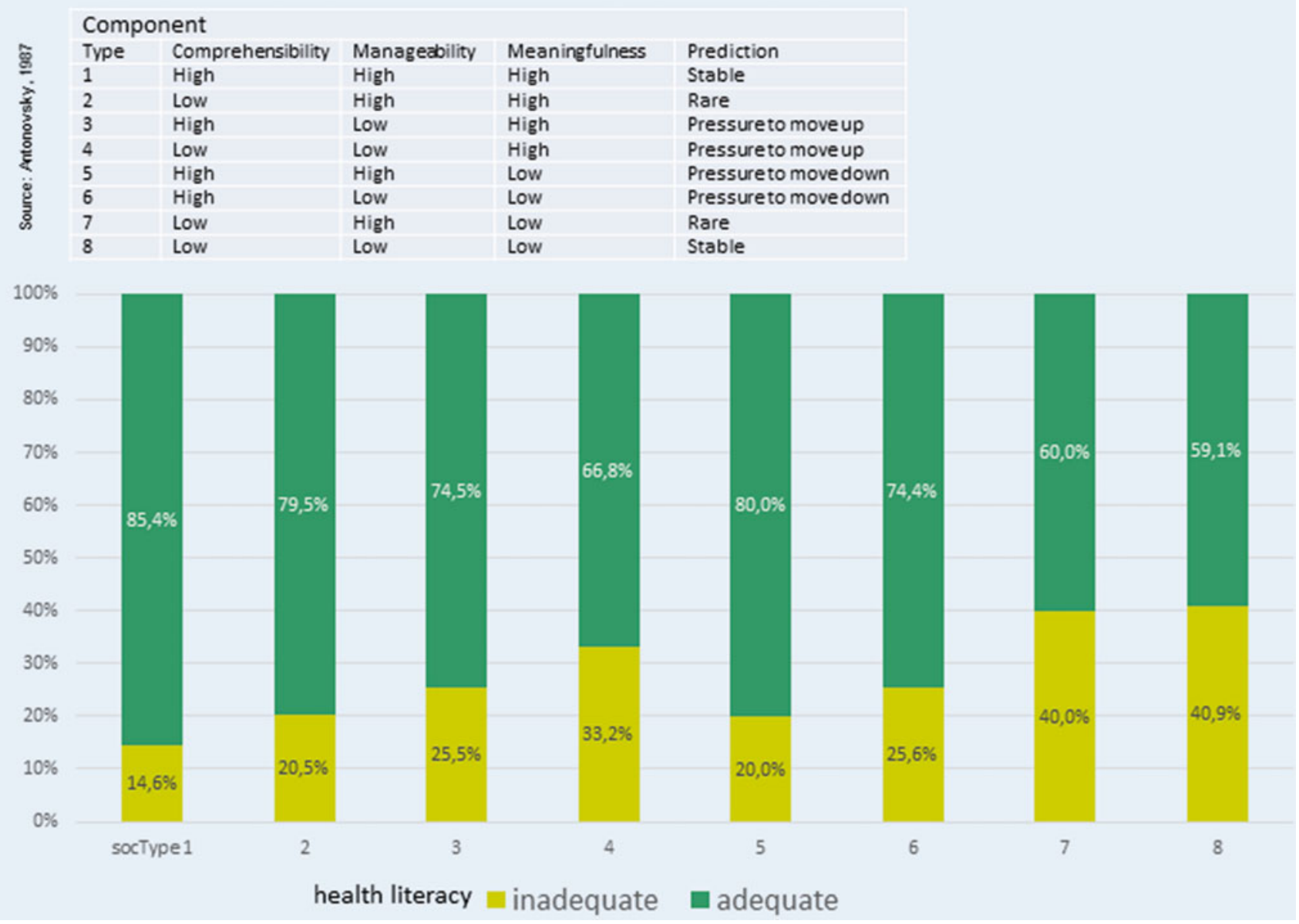

Fig. 46.4 Relationship between the sense of coherence: different types and the levels of health literacy (inadequate, adequate). Source: CrAdLiSa project, 2014 
Antonovsky's. Even today, it continues to be a challenge to have a common understanding in different countries speaking Portuguese, like Portugal or Brazil. New perspectives emerge like using the sense of coherence framework to address changes in lifestyles like smoking cessation or brucellosis prevention. Addressing children's well-being or focusing on mental health promotion are areas where salutogenesis can help achieve the goal of promoting health and favoring well-being in the Portuguese context.

Open Access This chapter is distributed under the terms of the Creative Commons Attribution-Noncommercial 2.5 License (http:// creativecommons.org/licenses/by-nc/2.5/) which permits any noncommercial use, distribution, and reproduction in any medium, provided the original author(s) and source are credited.

The images or other third party material in this chapter are included in the work's Creative Commons license, unless indicated otherwise in the credit line; if such material is not included in the work's Creative Commons license and the respective action is not permitted by statutory regulation, users will need to obtain permission from the license holder to duplicate, adapt or reproduce the material.

\section{References}

Antonovsky, A. (1979). Health, stress, and coping; new perspectives on mental and physical well-being. San Francisco: Jossey-Bass.

Antonovsky, A. (1984). A call for a new question-salutogenesis-and a proposed answer-the sense of coherence. Journal of Preventive Psychiatry, 2, 1-13.

Antonovsky, A. (1985). Health, stress and coping. London: Jossey-Bass. Antonovsky, A. (1987). Unraveling the mystery of health: How people manage stress and stay well. San Francisco: Jossey-Bass.

Brito I. (2008). Intervenção de Conscientização para Prevenção da Brucelose em Área Endémica. Porto: Instituto de Ciências Biomédicas Abel Salazar da Universidade do Porto. 2008. Dissertação elaborada no âmbito do Curso de Doutoramento ministrado pelo Instituto de Ciências Biomédicas Abel Salazar da Universidade do Porto.

Cavalheiro, G., \& Saboga-Nunes, L. (2014). Adolescents health literacy in the Portuguese context: The CrAdLiSa project (HLS-EUPT). Atencion Primaria, 46(1), 14-15.

Correia, M. (2014). Determinants of mother-baby relationship evaluated during pregnancy. Lisboa: Escola Nacional de Saúde Pública. UNL. Tese elaborada no âmbito do Curso de Doutoramento em Saúde Pública. Especialidade em Promoção da Saúde ministrado pela ENSP. UNL.

Dantas, R. (2007). Adaptação cultural e validação do Questionário de Senso de Coerência de Antonovsky em uma amostra de pacientes cardíacos brasileiros [tese livre-docência]. Ribeirão Preto: Escola de Enfermagem de Ribeirão Preto, Universidade de São Paulo.

Eurobarometer 429 (2015). Attitudes of Europeans towards Tobacco and Electronic Cigarettes, European Union. doi:10.2875/670456.

Ferreira, P. (Ed.). (2008). Tabagismo e dinâmicas de mudança. In Sistema de saúde português: riscos e incertezas: relatório de Primavera 2008 (pp. 181-191). Lisboa: Observatório Português dos Sistemas de Saúde.
Geada, M. (1994). Sentido interno de coerência, clima familiar e comportamentos de risco de consumo de drogas na adolescência. Análise Psicológica, 12(2-3), 315-321.

Gonçalves, P. M. (2010). Famílias de pessoas com síndromes psicóticas: Análise dimensional e avaliação da efectividade de uma intervenção em grupos para familiares [Families of people with psychotic disorders: Dimensional analysis and effectiveness of groups for relatives]. Tese de doutoramento, Faculdade de Ciências Médicas, Universidade Nova de Lisboa, Lisboa.

Gonçalves, P. M., \& Saboga-Nunes L. (2008). Sense of coherence in caregivers of the severely mentally ill - pathways for mental health promotion. In Proceedings of the 16th European Conference on Public Health (EUPHA), Lisbon (European Journal of Public Health, Vol. 18 Suppl 1, p 209; ISSN 1101-1262).

Karraker \& Grochowski. (2001). Families with future. In Resiliency: Families 'At Their Best' (Chapter 3). London: Routledge.

Lindstrom, B. (2001). O significado de resiliência. Adolescencia Latinoamericana, 2(3), 133-137. ISSN 1414-7130. http://raladolec.bvs.br/scielo.php?script $=$ sci_arttext $\&$ pid $=$ S1414$71302001000300006 \& \operatorname{lng}=$ es\&nrm=iso.

Marques, M. J., \& Gonçalves, P. M. (2014). Living with dementia: A review of the influence of sense of coherence. 22nd European Congress of Psychiatry. Munich, 1-4 March 2014. (European Psychiatry, 29(Suppl 1), 2014). doi:10.1016/S0924-9338(14)78518-9.

Pereira, M. M. (2010). Famílias de pessoas com síndromes psicóticas: Análise dimensional e avaliação da efectividade de uma intervenção em grupos para familiars.

RCAAP (2015). Open Access Portuguese institutional repositories. http://www.rcaap.pt/results.jsp.

Saboga-Nunes, L. (1998). Compreender o cidadão e fortalecê-lo na gestão do stress. Revista Portuguesa de Saúde Pública, 16(4), 25-31.

Saboga-Nunes, L. (1999). O sentido de coerência: Operacionalização de um conceito que influencia a saúde mental e a qualidade de vida. Lisboa: Escola Nacional de Saúde Pública. UNL. Dissertação elaborada no âmbito do Curso de Mestrado em Saúde Pública ministrado pela ENSP. UNL.

Saboga-Nunes, L. (2012). Web-assisted tobacco intervention in Portuguese: Intentions to make behavioural changes and behavioural changes. Lisboa: Escola Nacional de Saúde Pública. UNL. Tese elaborada no âmbito do Curso de Doutoramento em Saúde Pública. Especialidade em Promoção da Saúde ministrado pela ENSP. UNL.

Saboga-Nunes L. (2014). Literacia para a saúde e a conscientização da cidadania positiva. Revista Referência, III Série(Suplemento), 95-99.

Saboga-Nunes, L., Cavalheiro, G., Correia, S., Santos, A., Pinheiro, P., Bauer, U., et al. (2015). Adolescents' health literacy as a buffer in a crises context of a legionella outbreak in Portugal (CrAdLiSa project HLS-EU-PT). In Education and New Developments, World Institute for Advance Research and Science, 3rd END, 26-29 Jun 2015, Porto, Portugal 2015. Porto, Portugal: END, 2015, pp. 184-188. ISBN 978-989-99389-2-2. Disponível em: http://end-educationconference.org.

Saboga-Nunes, L., \& Sorensen, K. (2013). The European Health Literacy Survey (HLS-EU) and its Portuguese cultural adaptation and validation (HLS-PT). Atencion Primaria, 45, 46.

Saboga-Nunes, L., et al. (2014). Cross-cultural adaptation and validation to Portuguese of the European Health Literacy Survey (HLS-EU-PT). Atencion Primaria, 46(1), 12-13. 